\title{
Penerapan IoT untuk Kota Cerdas
}

\author{
Yoni Marine \\ Etunas Sukses Sistem \\ Devisi Pengembangan Sistem \\ Cirebon \\ yonimarine@etunas.co.id
}

\author{
Saluky \\ IAIN Syekh Nurjati Cirebon \\ Tadris Matematika \\ Cirebon \\ luke4line@gmail.com
}

\begin{abstract}
The Internet of Things (IoT) should be able to handle heterogeneous systems in a transparent and stable manner by providing open access to the selected data subset for the development of a large number of digital services. Building a common architecture for IoT is a very complex task, mainly because of the huge variety of devices, different technologies and services required. In this paper, we focus exclusively on large urban IoT systems. IoT's development is designed to support smart city's vision to utilize the most advanced communications technologies to support value-added services for city administration and for citizens. The paper provides a comprehensive survey of technologies, protocols, and architectures that allow for urban IoT.
\end{abstract}

Keywords : IoT, architecture, smart city

\section{PENDAHULUAN}

Perkembangan Internet of Things (IoT) menjadi paradigma komunikasi yang begitu pesat, di mana hampir semua objek dalam kehidupan sehari-hari akan dilengkapi dengan mikrokontroler, transceiver untuk komunikasi digital, dan tumpukan protokol yang sesuai untuk dapat berkomunikasi satu sama lain. Pengguna IoT menjadi bagian integral dari Internet [1]. Konsep IoT bertujuan untuk membuat Internet lebih merata penyebarannya. Selain itu, dengan memungkinkan akses dan interaksi yang mudah dengan berbagai perangkat seperti, peralatan rumah tangga, kamera pengawas, sensor pemantauan, aktuator, display, kendaraan, dan sebagainya, IoT akan mendorong pengembangan sejumlah aplikasi yang memanfaatkan jumlah dan variasi data yang sangat besar yang dihasilkan oleh objek-objek tersebut untuk memberikan layanan baru kepada warga, perusahaan, dan administrasi publik. Paradigma ini memang menemukan aplikasi di banyak bidang yang berbeda, seperti otomatisasi rumah, otomatisasi industri, bantuan medis, perawatan kesehatan keliling, bantuan orang tua, manajemen energi cerdas dan jaringan cerdas, otomotif, manajemen lalu lintas, dan banyak lainnya [2].

Namun, bidang aplikasi yang heterogen membuat identifikasi solusi yang mampu memenuhi persyaratan dari semua skenario aplikasi yang mungkin merupakan tantangan yang berat. Kesulitan ini telah menyebabkan kebutuhan yang berbeda dan, kadang-kadang, penyelesaian yang tidak kompatibel untuk realisasi praktis sistem IOT. Oleh karena itu, dari perspektif sistem, realisasi jaringan IoT, bersama dengan layanan dan perangkat jaringan backend yang dibutuhkan, masih kurang memiliki implementasi terbaik yang telah ditetapkan karena kebaruan dan kompleksitasnya. Selain kesulitan teknis, penerapan paradigma IoT juga terhambat oleh kurangnya model bisnis yang jelas dan diterima secara luas yang dapat menarik investasi untuk mempromosikan penyebaran teknologi ini [3].

Penerapan paradigma IoT ke konteks perkotaan adalah kepentingan khusus, karena ia merespon dorongan kuat dari banyak pemerintah nasional untuk mengadopsi solusi ICT dalam pengelolaan urusan publik, sehingga mewujudkan apa yang disebut konsep Kota cerdas[4]. Tujuan dari kota cerdas secara umum adalah untuk memanfaatkan sumber daya publik secara lebih baik, meningkatkan kualitas layanan yang ditawarkan kepada warga, sekaligus mengurangi biaya operasional publik dan administrasi. Tujuan ini dapat dikejar oleh penyebaran IoT perkotaan, yaitu infrastruktur komunikasi 
yang menyediakan akses terpadu, sederhana, dan ekonomis untuk sejumlah besar layanan publik, sehingga melepaskan potensi sinergi dan meningkatkan transparansi kepada warga. Sebuah IoT perkotaan, memang, dapat membawa sejumlah manfaat dalam pengelolaan dan optimalisasi layanan publik tradisional, seperti transportasi dan parkir, penerangan, pengawasan dan pemeliharaan area publik, pelestarian warisan budaya, pengumpulan sampah, rumah sakit, dan sekolah. Selain itu, ketersediaan berbagai jenis data, yang dikumpulkan oleh IoT perkotaan yang menyeluruh, juga dapat dimanfaatkan untuk meningkatkan transparansi dan mempromosikan tindakan pemerintah lokal terhadap warga, meningkatkan kesadaran masyarakat tentang status mereka. kota, merangsang partisipasi aktif warga dalam pengelolaan administrasi publik, dan juga merangsang penciptaan layanan baru pada mereka yang disediakan oleh IoT [5]. Oleh karena itu, penerapan paradigma IoT ke Kota cerdas sangat menarik bagi pemerintah lokal dan regional yang mungkin menjadi pengadopsi awal teknologi tersebut, sehingga bertindak sebagai katalis untuk mengadopsi paradigma IoT dalam skala yang lebih luas.

Tujuan dari makalah ini adalah untuk membahas model desain IoT perkotaan dengan menggambarkan karakteristik khusus dari IoT perkotaan, dan layanan yang dapat mendorong penerapan IoT perkotaan oleh pemerintah daerah. Kami melakukan analisis pendekatan berbasis web untuk desain layanan IoT, dan protokol dan teknologi terkait, membahas kesesuaian mereka untuk lingkungan Kota cerdas. Dalam hal ini, kami mendeskripsikan solusi teknis yang diadopsi untuk merealisasikan IoT pada kota cerdas.

\section{LANDASAN TEORI}

\section{A. Konsep Kota Cerdas}

Pengembangan Kota cerdas diperkirakan mencapai ratusan miliar dolar pada tahun 2020, dengan pengeluaran tahunan mencapai hampir 16 miliar. kebutuhan ini berasal dari interkoneksi sinergis sektor industri dan layanan utama, seperti smart governance, smart mobility, smart utility, smart building, dan smart environment. Sektor-sektor ini juga telah dipertimbangkan dalam proyek kota cerdas untuk menentukan kriteria peringkat yang dapat digunakan untuk menilai tingkat "kecerdasan" kota-kota. Meskipun demikian, pengembangan Kota cerdas belum benar-benar lepas landas, untuk sejumlah hambatan politik, teknis, dan keuangan [6].

Di bawah dimensi politik, hambatan utama adalah atribusi kekuatan pengambilan keputusan kepada pemangku kepentingan yang berbeda. Cara yang mungkin untuk menghilangkan hambatan ini adalah melembagakan seluruh keputusan dan proses eksekusi, memusatkan perencanaan strategis dan manajemen aspek kota cerdas menjadi satu departemen yang berdedikasi di kota [7].

Di sisi teknis, masalah yang paling relevan adalah ketidaktergantungan teknologi heterogen yang saat ini digunakan dalam perkembangan kota dan perkotaan. Dalam hal ini, visi IoT dapat menjadi blok bangunan untuk mewujudkan platform ICT berskala perkotaan bersatu, sehingga melepaskan potensi visi kota cerdas [8], [9].

Akhirnya, mengenai dimensi keuangan, model bisnis yang jelas masih kurang, meskipun beberapa inisiatif untuk mengisi kesenjangan ini baru-baru ini dilakukan [10]. Situasi ini diperburuk oleh situasi ekonomi global yang buruk, yang telah menentukan penyusutan umum investasi pada layanan publik. Situasi ini mencegah pengembangan Kota cerdas yang berpotensi besar menjadi kenyataan. Sebuah jalan keluar yang mungkin dari kebuntuan ini adalah untuk pertama-tama mengembangkan layananlayanan yang mengkonjugasikan utilitas sosial dengan pengembalian investasi yang sangat jelas, seperti parkir cerdas dan bangunan pintar, dan karenanya akan bertindak sebagai katalisator untuk layanan nilai tambah lainnya [10]. 


\section{B. Layanan Kota Cerdas}

Pada penelitian ini, kami mengulas beberapa layanan yang mungkin diaktifkan oleh paradigma IoT perkotaan dan yang memiliki minat potensial dalam konteks Kota Cerdas karena mereka dapat mewujudkan situasi yang menguntungkan untuk meningkatkan kualitas dan meningkatkan layanan ditawarkan kepada warga sambil membawa keuntungan ekonomis bagi administrasi kota dalam hal pengurangan biaya operasional [6]. Untuk lebih menghargai tingkat kematangan teknologi yang memungkinkan untuk layanan ini, kami melaporkan pada Tabel I pandangan sinoptik layanan dalam hal tipe yang disarankan dari jaringan yang akan digunakan, lalu lintas yang diharapkan dihasilkan oleh layanan. Dari tabel, jelas tampak bahwa, secara umum, realisasi praktis sebagian besar layanan semacam itu tidak terhalang oleh masalah teknis, tetapi oleh kurangnya arsitektur layanan dan komunikasi yang diterima secara luas yang dapat mengaburkan dari fitur khusus dari satu teknologi dan menyediakan akses yang terharmonisasi ke layanan.

Tabel 1 : Spesifikasi layanan untuk kota cerdas

\begin{tabular}{|l|l|l|}
\hline Service & Network type & Feasibility \\
\hline Structural health & 802.15 .4 ; wifi dan Ethernet & Mudah direalisasikan tetapi sulit diintegrasikan \\
\hline Waste management & Wifi; 3G dan 4G & Memungkinkan direalisasikan tetapi membutuhkan kotak sampah yang smart \\
\hline Air quality monitoring & $802.15 .4 ;$ wifi dan Bluetooth & Mudah direalisasikan tetapi masih kurang efektif \\
\hline Noise monitoring & 802.15 .4 dan Ethernet & Deteksi kebisingan masih sulit diimplementasikan \\
\hline Traffic congestion & $\begin{array}{l}\text { 802.15.4; Ethernet; wifi dan } \\
\text { Bluetooth }\end{array}$ & Membutuhkan realisasi antara kualitas udara dan pengawasan kebisingan \\
\hline City energy consumption & PLC dan Ethernet & Mudah direalisasikan tetapi harus diintegrasikan \\
\hline Smart parking & 802.15 .4 dan Ethernet & Sudah diimplementasikan diberbagai tempat \\
\hline Smart lighting & $802.15 .4 ;$ wifi dan Ethernet & Membutuhkan perubahan infrastruktur \\
\hline $\begin{array}{l}\text { Automation and salubrity } \\
\text { of public building }\end{array}$ & $802.15 .4 ;$ wifi dan Ethernet & Membutuhkan perubahan infrastruktur \\
\hline
\end{tabular}

Pemeliharaan Struktural Bangunan: Pemeliharaan yang tepat dari bangunan bersejarah kota membutuhkan pemantauan terus-menerus dari kondisi aktual setiap bangunan dan identifikasi area yang digunakan pihak eksternal. IoT perkotaan dapat menyediakan basis data terdistribusi untuk membangun pengukuran integritas struktural, yang dikumpulkan oleh sensor yang sesuai yang terletak di gedung, seperti sensor getaran dan deformasi untuk memantau stres bangunan, sensor agen atmosfer di daerah sekitarnya untuk memantau tingkat polusi, dan suhu dan sensor kelembaban untuk memiliki karakterisasi lengkap dari kondisi lingkungan [11]. Database ini harus mengurangi kebutuhan akan pengujian struktural periodik yang mahal oleh operator manusia dan akan memungkinkan tindakan pemeliharaan dan restorasi yang ditargetkan dan proaktif. Akhirnya, akan mungkin untuk menggabungkan getaran dan bacaan seismik untuk mempelajari lebih baik dan memahami dampak gempa bumi ringan pada bangunan kota. Database ini dapat diakses publik untuk membuat warga sadar akan perawatan yang diambil dalam melestarikan warisan sejarah kota. Realisasi praktis dari layanan ini, bagaimanapun, memerlukan pemasangan sensor di gedung-gedung dan sekitarnya dan interkoneksi mereka ke sistem kontrol, yang mungkin memerlukan investasi awal untuk menciptakan infrastruktur yang dibutuhkan.

Pengelolaan Limbah: Pengelolaan sampah adalah masalah utama di banyak kota modern, baik karena biaya layanan dan masalah penyimpanan sampah di tempat pembuangan sampah. Penetrasi yang lebih dalam dari solusi TIK dalam domain ini, bagaimanapun, dapat menghasilkan penghematan yang signifikan dan keuntungan ekonomis dan ekologis. Misalnya, penggunaan wadah limbah cerdas, yang mendeteksi tingkat beban dan memungkinkan optimalisasi rute truk pengumpul, dapat mengurangi biaya pengumpulan sampah dan meningkatkan kualitas daur ulang [12] .3 Untuk mewujudkan seperti pintar layanan pengelolaan limbah, IoT akan menghubungkan perangkat akhir, yaitu wadah limbah cerdas, ke pusat kendali tempat perangkat lunak pengoptimalan memproses data dan menentukan pengelolaan optimal armada truk pengumpul. 
Kualitas Udara: Dengan IoT perkotaan dapat menyediakan sarana untuk memantau kualitas udara di area yang ramai, taman, atau jalur kebugaran [13]. Selain itu, fasilitas komunikasi dapat disediakan untuk membiarkan aplikasi kesehatan yang berjalan di perangkat olahraga dihubungkan ke infrastruktur. Sedemikian rupa, orang selalu dapat menemukan tempat yang sesuai untuk kegiatan di luar ruangan dan dapat terus terhubung ke aplikasi pribadi yang mereka sukai. Realisasi layanan seperti itu mensyaratkan bahwa kualitas udara dan sensor polusi dikerahkan di seluruh kota dan bahwa data sensor dibuat tersedia untuk umum kepada warga.

Pemantauan Kebisingan: Kebisingan dapat dilihat sebagai bentuk polusi akustik sebanyak karbon oksida (CO) untuk udara. Dalam hal ini, pemerintah kota telah mengeluarkan undang-undang khusus untuk mengurangi jumlah kebisingan di pusat kota pada jam tertentu. IoT perkotaan dapat menawarkan layanan pemantauan kebisingan untuk mengukur jumlah kebisingan yang dihasilkan pada jam tertentu di tempat-tempat yang mengadopsi layanan [14]. Selain membangun peta ruang-waktu dari polusi suara di daerah tersebut, layanan seperti itu juga dapat digunakan untuk menegakkan keamanan publik, dengan menggunakan algoritma deteksi suara yang dapat mengenali, misalnya, suara kaca crash atau perkelahian. Layanan ini dapat meningkatkan ketenangan malam di kota dan kepercayaan dari pemilik perusahaan publik, meskipun pemasangan detektor suara atau mikrofon lingkungan cukup kontroversial, karena kekhawatiran privasi yang jelas untuk jenis pemantauan ini.

Kemacetan Lalu Lintas: Pada pemantauan kualitas udara dan kebisingan yang sama, layanan Kota cerdas yang mungkin dapat diaktifkan oleh IoT perkotaan terdiri dari pemantauan kemacetan lalu lintas di kota. Meskipun sistem pemantauan lalu lintas berbasis kamera sudah tersedia dan digunakan di banyak kota, komunikasi yang berdaya rendah dapat menyediakan sumber informasi yang lebih padat. Pemantauan lalu lintas dapat direalisasikan dengan menggunakan kemampuan penginderaan dan GPS yang dipasang pada kendaraan modern [15], dan juga mengadopsi kombinasi kualitas udara dan sensor akustik di sepanjang jalan yang diberikan. Informasi ini sangat penting bagi otoritas kota dan warga negara: bagi yang pertama untuk mendisiplinkan lalu lintas dan mengirim petugas di mana diperlukan dan untuk yang terakhir merencanakan terlebih dahulu rute untuk mencapai kantor atau untuk menjadwalkan lebih baik perjalanan belanja ke pusat kota.

Efisiensi Energi : Bersama dengan layanan pemantauan kualitas udara, IoT perkotaan dapat memberikan layanan untuk memantau konsumsi energi seluruh kota, sehingga memungkinkan pihak berwenang dan warga untuk mendapatkan pandangan yang jelas dan rinci tentang jumlah energi yang dibutuhkan oleh berbagai layanan (penerangan umum, transportasi, lampu lalu lintas, kamera kontrol, pemanasan / pendinginan gedung-gedung publik, dan sebagainya). Pada gilirannya, ini akan memungkinkan untuk mengidentifikasi sumber konsumsi energi utama dan menetapkan prioritas untuk mengoptimalkan perilaku mereka.

Smart Parking : Layanan parkir cerdas didasarkan pada sensor jalan dan display cerdas yang mengarahkan pengendara di sepanjang jalur terbaik untuk parkir di kota [16]. Manfaat yang didapat dari layanan ini bermacam-macam: waktu yang lebih cepat untuk menempatkan slot parkir berarti lebih sedikit emisi CO dari mobil, kemacetan lalu lintas yang lebih rendah, dan warga yang lebih bahagia. Layanan parkir pintar dapat langsung terintegrasi dalam infrastruktur IoT perkotaan, karena banyak perusahaan di Eropa menyediakan produk pasar untuk aplikasi ini. Selain itu, dengan menggunakan teknologi komunikasi jarak dekat, seperti Radio Frequency Identifiers (RFID) atau Near Field Communication (NFC), adalah mungkin untuk mewujudkan sistem verifikasi elektronik dari izin parkir di slot yang disediakan untuk penduduk atau orang cacat, sehingga menawarkan yang lebih baik layanan kepada warga yang secara sah dapat menggunakan slot tersebut dan alat yang efisien untuk dengan cepat menemukan pelanggaran.

Smart Lighting : Untuk mendukung direktif 20-20-20, optimalisasi efisiensi pencahayaan jalan adalah fitur penting. Secara khusus, layanan ini dapat mengoptimalkan intensitas lampu jalan sesuai dengan 
waktu hari, kondisi cuaca, dan kehadiran orang-orang. Agar dapat berfungsi dengan baik, layanan seperti itu perlu memasukkan lampu jalan ke infrastruktur Kota cerdas. Juga dimungkinkan untuk memanfaatkan peningkatan jumlah titik yang terhubung untuk menyediakan koneksi WiFi kepada warga. Selain itu, sistem deteksi gangguan akan mudah direalisasikan di atas pengendali lampu jalan.

Otomatisasi dan Kenyamanan Bangunan Publik: Aplikasi penting lainnya dari teknologi IoT adalah pemantauan konsumsi energi dan kenyamanan lingkungan di gedung-gedung publik (sekolah, kantor administrasi, dan museum) dengan menggunakan berbagai jenis sensor dan aktuator yang mengendalikan lampu , suhu, dan kelembaban. Dengan mengendalikan parameter ini, memang dimungkinkan untuk meningkatkan tingkat kenyamanan orang-orang yang tinggal di lingkungan ini, yang mungkin juga memiliki pengembalian positif dalam hal produktivitas, sementara mengurangi biaya untuk pemanasan / pendinginan [17].

\section{Arsitektur Iot PerkotaAn}

Dari analisis layanan yang dijelaskan dalam Bagian II, jelas terlihat bahwa sebagian besar layanan Kota cerdas didasarkan pada arsitektur terpusat, di mana perangkat perangkat yang padat dan heterogen yang ditempatkan di daerah perkotaan menghasilkan berbagai jenis data yang kemudian dikirimkan melalui teknologi komunikasi yang sesuai ke pusat kendali, tempat penyimpanan dan pemrosesan data dilakukan.

Karakteristik utama dari infrastruktur IoT perkotaan, karenanya, adalah kemampuannya mengintegrasikan berbagai teknologi dengan infrastruktur komunikasi yang ada untuk mendukung evolusi progresif IoT, dengan interkoneksi perangkat lain dan realisasi fungsionalitas dan layanan baru. Aspek mendasar lainnya adalah kebutuhan untuk membuat (sebagian) data yang dikumpulkan oleh IoT perkotaan yang mudah diakses oleh pihak berwenang dan warga, untuk meningkatkan daya tanggap pihak berwenang terhadap masalah kota, dan untuk meningkatkan kesadaran dan partisipasi warga dalam masalah publik [ 9].

Di bagian lain dari bagian ini, kami mendeskripsikan komponen yang berbeda dari sistem IoT perkotaan, seperti yang digambarkan dalam Gambar 1. Kami mulai mendeskripsikan pendekatan layanan web untuk desain layanan IoT, yang membutuhkan penyebaran lapisan protokol yang sesuai di berbagai elemen jaringan, seperti yang ditunjukkan dalam tumpukan protokol yang digambarkan pada Gambar. 1, selain elemen kunci dari arsitektur.

\section{A. Pendekatan Layanan Web untuk Arsitektur Layanan IoT}

Meskipun di domain IoT banyak standar yang berbeda masih berjuang untuk menjadi referensi dan yang paling diadopsi, di bagian ini kami fokus secara khusus pada standar IETF karena mereka terbuka dan bebas royalti, didasarkan pada praktik terbaik Internet, dan dapat mengandalkan komunitas luas. 


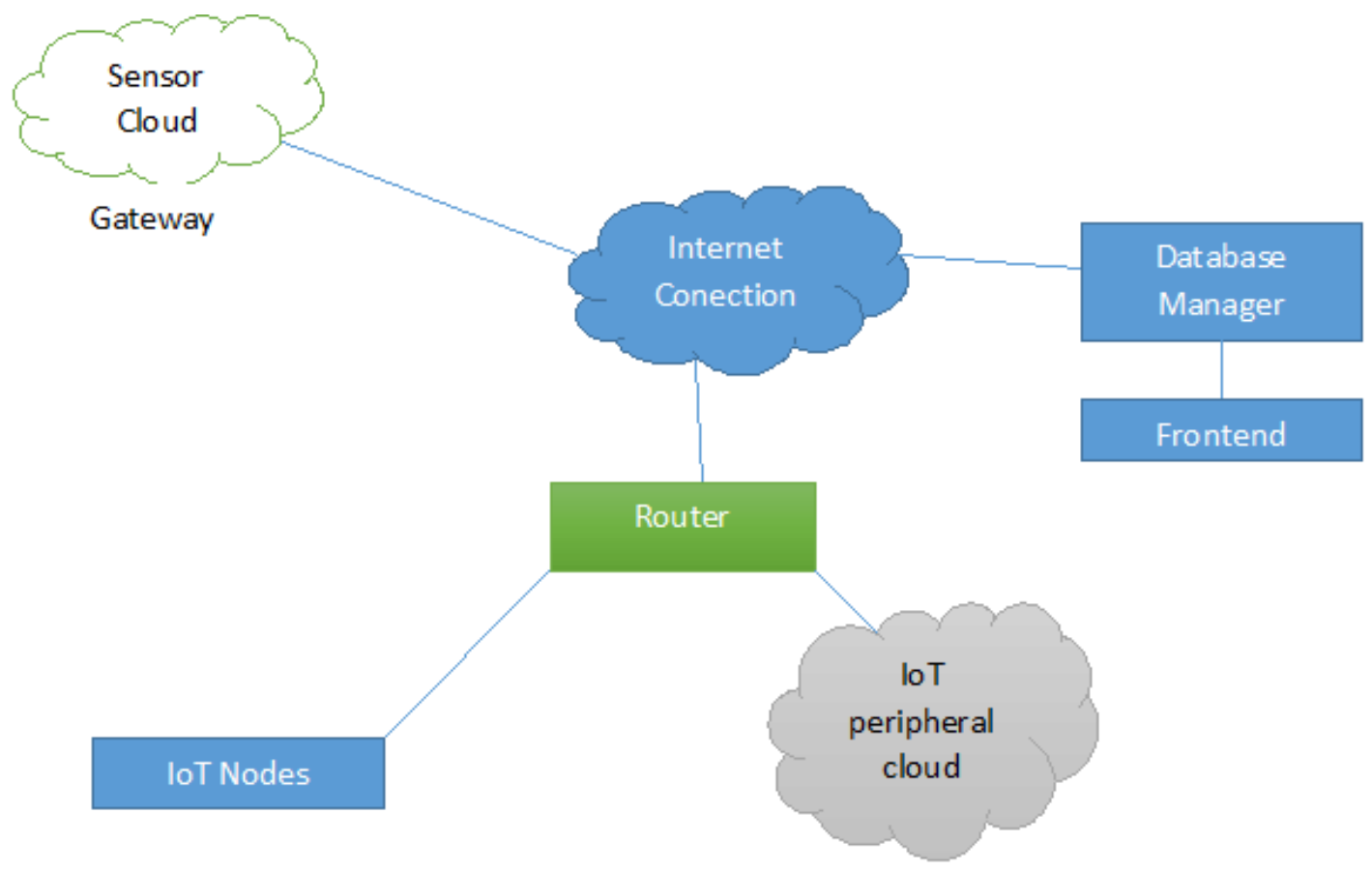

Gambar. 1. Representasi konseptual dari jaringan IoT perkotaan berdasarkan pendekatan layanan.

Standar IoT menggunakan arsitektur layanan web untuk layanan IoT, yang telah banyak didokumentasikan dalam literatur sebagai pendekatan yang sangat menjanjikan dan fleksibel. Bahkan, layanan web memungkinkan untuk mewujudkan sistem yang fleksibel dan interoperable yang dapat diperluas ke node IoT, melalui adopsi paradigma berbasis web yang dikenal sebagai Representational State Transfer (ReST) [18]. Layanan IoT yang dirancang sesuai dengan paradigma ReST menunjukkan kemiripan yang sangat kuat dengan layanan web tradisional, sehingga sangat memudahkan adopsi dan penggunaan IoT oleh pengguna akhir dan pengembang layanan, yang akan dapat dengan mudah menggunakan kembali sebagian besar pengetahuan yang didapat dari web tradisional teknologi dalam pengembangan layanan untuk jaringan yang berisi objek pintar.

Dalam arsitektur protokol kita dapat membedakan tiga lapisan fungsional yang berbeda, yaitu (i) Data, (ii) Aplikasi / Transportasi, dan (iii) Jaringan, yang mungkin memerlukan entitas khusus untuk mengoperasikan transcoding antara dibatasi dan tidak dibatasi format dan protokol. Di sisa bagian ini, kami menetapkan secara lebih rinci persyaratan pada masing-masing dari tiga lapisan fungsional untuk menjamin interoperabilitas di antara bagian-bagian yang berbeda dari sistem.

\section{Format Data}

Seperti disebutkan, paradigma IoT perkotaan menetapkan persyaratan khusus dalam hal aksesibilitas data. Dalam arsitektur yang didasarkan pada layanan web, pertukaran data biasanya disertai dengan deskripsi konten yang ditransfer dengan menggunakan bahasa representasi semantik, di mana Bahasa Markup yang eXtensible (XML) mungkin yang paling umum. Namun demikian, ukuran pesan XML sering terlalu besar untuk kapasitas terbatas perangkat khas untuk IoT. Selain itu, sifat teks representasi XML membuat penguraian pesan oleh perangkat yang dibatasi CPU lebih kompleks dibandingkan dengan format biner. Untuk alasan ini, kelompok kerja World Wide Web Consortium (W3C) 7 telah mengusulkan format EXI [19], yang memungkinkan bahkan untuk perangkat yang sangat terbatas untuk secara native mendukung dan menghasilkan pesan menggunakan format data terbuka yang kompatibel dengan XML.

EXI mendefinisikan dua jenis pengkodean, yaitu skema-kurang dan skema-informasi. Sementara pengkodean skema-kurang dihasilkan langsung dari data XML dan dapat diterjemahkan oleh setiap 
entitas EXI tanpa pengetahuan sebelumnya tentang data, pengkodean skema-informasi mengasumsikan bahwa dua prosesor EXI berbagi skema XML sebelum pengkodean aktual dan decoding dapat terjadi. Skema bersama ini memungkinkan untuk menetapkan pengidentifikasi numerik ke tag XML dalam skema dan membangun tata bahasa EXI pada pengkodean tersebut. Seperti yang dibahas dalam [20], sebuah prosesor EXI dengan tujuan skema informasi umum dapat dengan mudah diintegrasikan bahkan di perangkat yang sangat terbatas, memungkinkan mereka untuk menafsirkan format EXI dan, karenanya, memungkinkan untuk membangun node IoT multiguna bahkan dari perangkat yang sangat terbatas. Menggunakan pendekatan skema informasi, bagaimanapun, membutuhkan perawatan tambahan dalam pengembangan aplikasi lapisan yang lebih tinggi, karena pengembang perlu mendefinisikan Skema XML untuk pesan yang terlibat dalam aplikasi dan menggunakan prosesor EXI yang mendukung mode operasi ini. Detail lebih lanjut tentang EXI dan pemrosesan berdasarkan skema dapat ditemukan di [20].

Integrasi beberapa sumber data XML / EXI ke dalam sistem IoT dapat diperoleh dengan menggunakan database yang biasanya dibuat dan dikelola oleh aplikasi tingkat tinggi. Bahkan, aplikasi IoT umumnya membangun database dari node yang dikendalikan oleh aplikasi dan, seringkali, dari data yang dihasilkan oleh node tersebut. Basis data memungkinkan untuk mengintegrasikan data yang diterima oleh perangkat IoT apa pun untuk menyediakan layanan khusus untuk aplikasi yang dibangun. Kerangka umum untuk membangun aplikasi web IoT sesuai dengan panduan yang diuraikan dalam bagian ini telah diusulkan di [21], di mana penulis juga menyarankan untuk mengeksploitasi kemampuan Asynchronous JavaScript dan XML (AJAX) dari browser web modern yang memungkinkan komunikasi langsung antara browser dan simpul IoT akhir, mendemonstrasikan internetworking penuh dari tumpukan protokol dan sifat data terbuka dari pendekatan yang diusulkan.

\section{Lapisan Aplikasi dan Transportasi}

Sebagian besar lalu lintas yang melintasi Internet saat ini dilakukan di lapisan aplikasi oleh HTTP melalui TCP. Namun, verbositas dan kompleksitas dari HTTP asli membuatnya tidak cocok untuk penyebaran langsung pada perangkat IOT yang dibatasi. Untuk lingkungan seperti itu, pada kenyataannya, format HTTP yang dapat dibaca manusia, yang telah menjadi salah satu alasan keberhasilannya dalam jaringan tradisional, ternyata menjadi faktor pembatas karena jumlah besar yang sangat berkorelasi (dan karenanya, redundant) data. Selain itu, HTTP biasanya bergantung pada protokol transport TCP yang, bagaimanapun, tidak mengukur dengan baik pada perangkat yang dibatasi, menghasilkan kinerja yang buruk untuk arus data kecil di lingkungan yang rugi.

Protokol CoAP [22] mengatasi kesulitan-kesulitan ini dengan mengajukan format biner yang diangkut melalui UDP, hanya menangani transmisi ulang yang diperlukan untuk menyediakan layanan yang dapat diandalkan. Selain itu, CoAP dapat dengan mudah interoperate dengan HTTP karena: (i) mendukung metode ReST dari HTTP (GET, PUT, POST, dan DELETE), (ii) ada korespondensi satuke-satu antara kode respon dari dua protokol, dan (iii) opsi CoAP dapat mendukung berbagai skenario penggunaan HTTP.

Meskipun host Internet biasa dapat secara native mendukung CoAP untuk langsung berbicara dengan perangkat IoT, solusi yang paling umum dan mudah interoperable membutuhkan penyebaran perantara HTTP-CoAP, juga dikenal sebagai proxy silang yang dapat menerjemahkan permintaan / tanggapan secara langsung di antara dua protokol, sehingga memungkinkan interoperasi transparan dengan perangkat dan aplikasi HTTP asli [23].

\section{Lapisan Jaringan}

IPv4 adalah teknologi pengalamatan terkemuka yang didukung oleh host Internet. Namun, IANA, organisasi internasional yang menetapkan alamat IP di tingkat global, baru-baru ini mengumumkan penghapusan blok alamat IPv4. Jaringan IoT, pada gilirannya, diharapkan untuk menyertakan miliaran 
node, yang masing-masing harus (secara prinsip) dapat dialamati secara unik. Solusi untuk masalah ini ditawarkan oleh standar IPv6 [24], yang menyediakan bidang alamat 128-bit, sehingga memungkinkan untuk menetapkan alamat IPv6 unik ke setiap node yang mungkin dalam jaringan IOT.

Sementara, di satu sisi, ruang alamat IPv6 yang sangat besar memungkinkan untuk menyelesaikan masalah pengalamatan di IoT; di sisi lain, ia memperkenalkan overhead yang tidak kompatibel dengan kemampuan langka dari node yang dibatasi. Masalah ini dapat diatasi dengan mengadopsi 6LoWPAN [25], [26], yang merupakan format kompresi yang ditetapkan untuk header IPv6 dan UDP melalui jaringan dengan daya rendah. Sebuah router perbatasan, yang merupakan perangkat yang langsung terhubung ke jaringan 6LoWPAN, secara transparan melakukan konversi antara IPv6 dan 6LoWPAN, menerjemahkan paket IPv6 apa pun yang ditujukan untuk node di jaringan 6LoWPAN ke dalam paket dengan format kompresi header 6LoWPAN, dan mengoperasikan terjemahan inversi dalam arah yang berlawanan.

Sementara penyebaran router perbatasan 6LoWPAN memungkinkan interaksi transparan antara node IoT dan host IPv6 di Internet, interaksi dengan host IPv4 saja tetap menjadi masalah. Lebih khusus lagi, masalahnya adalah menemukan cara untuk mengatasi host IPv6 spesifik menggunakan alamat IPv4 dan meta-data lainnya yang tersedia dalam paket. Berikut ini, kami menyajikan pendekatan yang berbeda untuk mencapai tujuan ini.

Pemetaan URI. Teknik pemetaan Universal Resource Identifier (URI) juga dijelaskan dalam [23]. Teknik ini melibatkan tipe tertentu proxy cross HTTP-CoAP, proxy silang terbalik. Proksi ini berfungsi sebagai server web terakhir untuk klien HTTP / IPv4 dan sebagai klien asli ke server web CoAP / IPv6. Karena mesin ini harus ditempatkan di bagian jaringan di mana konektivitas IPv6 hadir untuk memungkinkan akses langsung ke simpul IoT akhir, konversi IPv4 / IPv6 diselesaikan secara internal oleh fungsi pemetaan URI yang diterapkan.

\section{B. Teknologi Lapisan Tautan}

Sistem IoT perkotaan, karena area penyebarannya yang sangat luas, membutuhkan seperangkat teknologi lapisan tautan yang dapat dengan mudah menjangkau area geografis yang luas dan, pada saat yang sama, mendukung kemungkinan jumlah lalu lintas yang besar dari agregasi yang sangat tinggi jumlah arus data yang lebih kecil. Untuk alasan ini, teknologi lapisan tautan memungkinkan realisasi sistem IoT perkotaan diklasifikasikan ke dalam teknologi yang tidak dibatasi dan dibatasi. Kelompok pertama mencakup semua teknologi komunikasi tradisional LAN, MAN, dan WAN, seperti Ethernet, WiFi, serat optik, Broadband Power Line Communication (PLC), dan teknologi seluler seperti UMTS dan LTE. Mereka umumnya dicirikan oleh keandalan yang tinggi, latensi rendah, dan tingkat transfer tinggi (urutan Mbit / s atau lebih tinggi), dan karena kompleksitas yang melekat dan konsumsi energi mereka umumnya tidak cocok untuk node IOT perifer.

Teknologi lapisan fisik dan tautan yang dibatasi, sebaliknya, umumnya dicirikan oleh konsumsi energi yang rendah dan tingkat transfer yang relatif rendah, biasanya lebih kecil dari $1 \mathrm{Mbit} / \mathrm{dtk}$. Solusi yang lebih menonjol dalam kategori ini adalah IEEE 802.15.4 [27], [28] Bluetooth dan Bluetooth Low Energy, 8 IEEE 802.11 Daya Rendah, PLC [29], NFC dan RFID [30]. Tautan ini biasanya menunjukkan latensi yang panjang, terutama karena dua faktor: 1) tingkat transmisi yang secara intrinsik rendah pada lapisan fisik dan 2) kebijakan hemat daya yang diterapkan oleh node untuk menghemat energi, yang biasanya melibatkan bersepeda tugas dengan periode aktif pendek. 


\section{Perangkat}

Kami akhirnya menggambarkan perangkat yang penting untuk mewujudkan IoT perkotaan, diklasifikasikan berdasarkan posisi yang mereka tempati dalam arus komunikasi.

\section{Server Backend}

Server backend terletak di pusat kontrol, tempat data dikumpulkan, disimpan, dan diproses untuk menghasilkan layanan bernilai tambah. Pada prinsipnya, server backend tidak wajib untuk sistem IoT untuk beroperasi dengan baik, meskipun mereka menjadi komponen mendasar dari IoT perkotaan di mana mereka dapat memfasilitasi akses ke layanan kota cerdas dan membuka data melalui infrastruktur jaringan legacy. Sistem backend yang biasanya dipertimbangkan untuk berinteraksi dengan pengumpan data IoT meliputi yang berikut ini.

Sistem manajemen basis data: Sistem ini bertugas menyimpan sejumlah besar informasi yang dihasilkan oleh nodus perifer IoT, seperti sensor. Tergantung pada skenario penggunaan tertentu, beban pada sistem ini bisa sangat besar, sehingga diperlukan dimensi sistem backend yang tepat.

Situs web: penggunaan web yang telah umum menjadikannya opsi pertama untuk mengaktifkan interoperasi antara sistem IoT dan "konsumen data", misalnya, otoritas publik, operator layanan, penyedia utilitas, dan warga umum.

Sistem perencanaan sumber daya perusahaan (ERP): Komponen ERP mendukung berbagai fungsi bisnis dan merupakan alat yang berharga untuk mengelola aliran informasi di seluruh organisasi yang kompleks, seperti administrasi kota. Interfacing komponen ERP dengan sistem manajemen database yang mengumpulkan data yang dihasilkan oleh IoT memungkinkan manajemen yang lebih sederhana dari jumlah data yang sangat besar yang dikumpulkan oleh IoT, sehingga memungkinkan untuk memisahkan arus informasi berdasarkan sifat dan relevansinya dan mempermudah pembuatannya. layanan baru.

\section{Gateway}

Gateway berperan untuk menghubungkan perangkat akhir ke infrastruktur komunikasi utama dari sistem. Dengan mengacu pada arsitektur protokol konseptual gateway diperlukan untuk menyediakan terjemahan protokol dan pemetaan fungsional antara protokol yang tidak dibatasi dan rekan-rekannya yang dibatasi, yaitu XML-EXI, HTTP-CoAP, IPv4 / v6- 6LoWPAN.

Perhatikan bahwa sementara semua terjemahan ini mungkin diperlukan untuk memungkinkan interoperabilitas dengan perangkat periferal dan stasiun kontrol IoT, tidak perlu mengkonsentrasikan semuanya dalam satu gateway. Sebaliknya, mungkin, dan kadang-kadang nyaman, untuk mendistribusikan tugas terjemahan melalui perangkat yang berbeda dalam jaringan. Sebagai contoh, proxy HTTP-CoAP tunggal dapat digunakan untuk mendukung beberapa router perbatasan 6LoWPAN.

Perangkat gateway juga akan menyediakan interkoneksi antara teknologi lapisan tautan yang tidak dibatasi, terutama digunakan dalam jaringan IoT inti, dan teknologi yang dibatasi, sebagai gantinya, menyediakan konektivitas di antara nodus perifer IoT.

\section{IoT Peripheral Nodes}

Perangkat IoT bertanggung jawab menghasilkan data untuk dikirim ke pusat kendali, yang biasanya disebut node perifer IoT atau, lebih sederhana disebut nodus IoT. Secara umum, biaya perangkat ini cukup murah, tergantung pada jenis dan jumlah sensor / aktuator yang dipasang di board. Node-node IOT dapat diklasifikasikan berdasarkan sejumlah besar karakteristik, seperti mode powering, peran 
jaringan, peralatan sensor / aktuator, dan teknologi lapisan tautan yang didukung. Node IoT yang paling terbatas kemungkinan adalah RFID yang, meskipun kemampuannya sangat terbatas, masih dapat memainkan peran penting dalam sistem IOT, terutama karena biaya yang sangat rendah dan sifat pasif dari perangkat keras komunikasi mereka, yang tidak banyak memerlukan sumber energi internal. Aplikasi khas RFID adalah identifikasi objek dengan pembacaan kedekatan, yang dapat digunakan untuk logistik, pemeliharaan, pemantauan, dan layanan lainnya.

Perangkat seluler, seperti ponsel pintar, PC tablet, atau laptop, juga dapat menjadi bagian penting dari IoT perkotaan, menyediakan cara lain untuk berinteraksi dengannya. Misalnya, transceiver NFC yang terintegrasi dalam smartphone generasi terakhir dapat digunakan untuk mengidentifikasi objek yang ditandai, sementara layanan geolokasi yang disediakan oleh sistem operasi paling umum untuk perangkat seluler dapat memperkaya informasi konteks yang terkait dengan objek tersebut. Selain itu, perangkat seluler dapat memberikan akses ke IoT dengan cara yang berbeda, misalnya, 1) melalui koneksi IP yang disediakan oleh layanan tautan data seluler atau 2) pengaturan koneksi langsung dengan beberapa objek dengan menggunakan teknologi nirkabel jarak pendek, seperti sebagai Bluetooth Low Energy, WiFi berdaya rendah, atau IEEE 802.15.4. Selain itu, dimungkinkan untuk mengembangkan aplikasi khusus untuk perangkat seluler yang dapat memudahkan interaksi dengan objek IoT, dan dengan sistem secara keseluruhan.

\section{KESIMPULAN}

Dalam makalah ini, kami menganalisis solusi yang tersedia saat ini untuk penerapan IoT perkotaan. Teknologi yang dibahas mendekati standar, dan pemain industri sudah aktif dalam produksi perangkat yang memanfaatkan teknologi ini untuk memungkinkan aplikasi yang menarik, seperti yang dijelaskan dalam Bagian II. Faktanya, sementara rentang pilihan desain untuk sistem IoT cukup lebar, set protokol terbuka dan standar secara signifikan lebih kecil. Teknologi yang memungkinkan, lebih jauh lagi, telah mencapai tingkat kematangan yang memungkinkan realisasi praktis solusi dan layanan IoT, mulai dari uji coba lapangan yang diharapkan akan membantu menghilangkan ketidakpastian yang masih menghalangi adopsi besar-besaran paradigma IoT.

\section{REFERENSI}

[1] L. Atzori, A. Iera, and G. Morabito, "The internet of things: A survey," Comput. Netw., vol. 54, no. 15, pp. 2787-2805, 2010.

[2] P. Bellavista, G. Cardone, A. Corradi, and L. Foschini, "Convergence of MANET and WSN in IoT urban scenarios," IEEE Sens. J., vol. 13, no. 10, pp. 3558-3567, Oct. 2013.

[3] A. Laya, V. I. Bratu, and J. Markendahl, "Who is investing in machine-tomachine communications?” in Proc. 24th Eur. Reg. ITS Conf., Florence, Italy, Oct. 2013, pp. 20-23.

[4] H. Schaffers, N. Komninos, M. Pallot, B. Trousse, M. Nilsson, and A. Oliveira, "Smart cities and the future internet: Towards cooperation frameworks for open innovation," The Future Internet, Lect. Notes Comput. Sci., vol. 6656, pp. 431-446, 2011.

[5] D. Cuff, M. Hansen, and J. Kang, "Urban sensing: Out of the woods," Commun. ACM, vol. 51, no. 3, pp. 24-33, Mar. 2008.

[6] M. Dohler, I. Vilajosana, X. Vilajosana, and J. Llosa, "Smart Cities: An action plan," in Proc. Barcelona Smart Cities Congress, Barcelona, Spain, Dec. 2011, pp. 1-6.

[7] I. Vilajosana, J. Llosa, B. Martinez, M. Domingo-Prieto, A. Angles, and X. Vilajosana, "Bootstrapping smart cities through a self-sustainable model based on big data flows," IEEE Commun. Mag., vol. 51, no. 6, pp. 128-134, Jun. 2013. 
[8] J. M. Hernández-Muñoz, J. B. Vercher, L. Muñoz, J. A. Galache, M. Presser, L. A. Hernández Gómez, and J. Pettersson, "Smart Cities at the forefront of the future Internet," The Future Internet, Lect. Notes Comput. Sci., vol. 6656, pp. 447-462, 2011.

[9] C. E. A. Mulligan and M. Olsson, "Architectural implications of smart city business models: An evolutionary perspective,” IEEE Commun. Mag., vol. 51, no. 6, pp. 80-85, Jun. 2013.

[10] N. Walravens and P. Ballon, "Platform business models for smart cities: From control and value to governance and public value,” IEEE Commun. Mag., vol. 51, no. 6, pp. 72-79, Jun. 2013.

[11] J. P. Lynch and J. L. Kenneth, "A summary review of wireless sensors and sensor networks for structural health monitoring," Shock and Vibration Digest, vol. 38, no. 2, pp. 91-130, 2006.

[12] T. Nuortio, J. Kytöjoki, H. Niska, and O. Bräysy, "Improved route planning and scheduling of waste collection and transport," Expert Syst. Appl., vol. 30, no. 2, pp. 223-232, Feb. 2006.

[13] A. R. Al-Ali, I. Zualkernan, and F. Aloul, "A mobile GPRS-sensors array for air pollution monitoring,” IEEE Sensors J., vol. 10, no. 10, pp. 1666-1671, Oct. 2010.

[14] N. Maisonneuve, M. Stevens, M. E. Niessen, P. Hanappe, and L. Steels, "Citizen noise pollution monitoring," in Proc. 10th Annu. Int. Conf. Digital Gov. Res.: Soc. Netw.: Making Connec. Between Citizens, Data Gov., 2009, pp. 96-103.

[15] X. Li, W. Shu, M. Li, H.-Y. Huang, P.-E. Luo, and M.-Y.Wu, "Performance evaluation of vehiclebased mobile sensor networks for traffic monitoring," IEEE Trans. Veh. Technol., vol. 58, no. 4, pp. 1647-1653, May 2009.

[16] S. Lee, D. Yoon, and A. Ghosh, "Intelligent parking lot application using wireless sensor networks," in Proc. Int. Symp. Collab. Technol. Syst., Chicago, May 19-23, 2008, pp. 48-57.

[17] W. Kastner, G. Neugschwandtner, S. Soucek, and H. M. Newmann, "Communication systems for building automation and control,” in Proc. IEEE, Jun. 2005, vol. 93, no. 6, pp. 1178-1203.

[18] R. T Fielding, "Architectural styles and the design of network-based software architectures," (The Representational State Transfer (REST)) Ph.D. dissertation, pp 76-85, Dept. Inf. Comput. Sci. Univ. California, Irvine, 2000. [Online]. Available: http://www.ics.uci.edu/ fielding/pubs/ dissertation/top.htm.

[19] "Efficient XML Interchange (EXI) Format 1.0," J. Schneider, T. Kamiya, D. Peintner, and R. Kyusakov, Eds., 2nd ed. World Wide Web Consortium, Feb. 11, 2014. [Online]. Available: http://www.w3.org/TR/exi/.

[20] A. P. Castellani, N. Bui, P. Casari, M. Rossi, Z. Shelby, and M. Zorzi, "Architecture and protocols for the Internet of Things: A case study," in Proc. 8th IEEE Int. Conf. Pervasive Comput. Commun. Workshops (PERCOM Workshops), 2010, pp. 678-683.

[21] A. P. Castellani, M. Dissegna, N. Bui, and M. Zorzi, "WebIoT: A web application framework for the internet of things," in Proc. IEEE Wireless Commun. Netw. Conf. Workshops, Paris, France, 2012.

[22] Z. Shelby, K. Hartke, C. Bormann, and B. Frank, Constrained application protocol (CoAP), draftietf-core-coap-18 (work in progress), s.l.: IETF 2013. [Online]. Available: http://tools.ietf.org/html/draft-ietf-corecoap-18.

[23] A. Castellani, S. Loreto, A. Rahman, T. Fossati, and E. Dijk, Best practices for HTTP-CoAP mapping implementation, draft-castellani-core-httpmapping-07 (work in progress), s.l.: IETF 2013. [Online]. Available: https://tools.ietf.org/html/draft-castellani-core-http-mapping-02. 
[24] S. Deering and R. Hinden, Internet Protocol, Version 6 (IPv6) Specification, RFC2460, s.1.: IETF Dec. 1998. [Online]. Available: https://www.ietf.org/rfc/rfc2460.txt.

[25] G. Montenegro, N. Kushalnagar, J. Hui, and D. Culler, Transmission of IPv6 packets over IEEE 802.15.4 networks, RFC4944, s.l.: IETF Sep. 2007. [Online]. Available: http://tools.ietf.org/html/rfc4944.

[26] J. Hui and P. Thubert, Compression format for IPv6 datagrams over IEEE 802.15.4-Based Networks, RFC6282, s.1.: IETF Sep. 2011. [Online]. Available: http://tools.ietf.org/html/rfc6282.

[27] IEEE Standard for Local and Metropolitan Area Networks-Part 15.4: Low-Rate Wireless Personal Area Networks (LR-WPANs), IEEE Standard 802.15.4-2011.

[28] IEEE 802.15 WPAN Task Group 4e (TG4e), IEEE Standard 802.15.4b, 2014.

[29] IEEE Communications Society, P1901.2-2013 - Standard for Low Frequency (less than $500 \mathrm{kHz}$ ) Narrow Band Power Line Communications for Smart Grid Applications, IEEE Standard P1901.2-2013.

[30] ISO/IEC 14443-1:2008, Identification Cards - Contactless Integrated Circuit Cards-Proximity Cards-Part 1: Physical Characteristics. [Online]. Available: http://www.wg8.de/wg8n1716_17n3994_Notification__ for_Ballot_FDIS_144431_2008_FDAM1.pdf. [31] A. P. Castellani, M. Gheda, N. Bui, M. Rossi, and M. Zorzi, "Web services for the Internet of Things through CoAP and EXI," in Proc. IEEE Int. Conf. Commun. (ICC 2001), Kyoto, Japan, 2011.

[32] P. Casari et al., "The WIreless SEnsor networks for city-Wide Ambient Intelligence (WISE-WAI) project," MDPI J. Sensors, vol. 9, no. 6, pp. 4056-4082, Jun. 2009. [Online]. Available: http://www.mdpi.com/1424-8220/9/6/4056.

[33] N. Bressan, L. Bazzaco, N. Bui, P. Casari, L. Vangelista, and M. Zorzi, "The deployment of a smart monitoring system using wireless sensor and actuator networks," in Proc. IEEE Smart Grid. Comm., Gaithersburg, MD, 2010, pp. 49-54.

[34] N. Bui and M. Zorzi, "Health care applications: A solution based on the Internet of Things," in Proc. ISABEL, Barcelona, Spain, Oct. 2011, pp. 1-5.

[35] T. Winter, P. Thubert, A. Brandt, J. Hui, R. Kelsey, K. Pister, R. Struik, J. P. Vasseur, and R. Alexander, RPL: IPv6 routing protocol for low-power and lossy networks, RFC6550, s.1.: IETF Mar. 2012. [Online]. Available: http://tools.ietf.org/html/rfc6.

[36] R. Bonetto, N. Bui, V. Lakkundi, A. Olivereau, A. Serbanati, and M. Rossi, "Secure communication for smart IoT Objects: Protocol stacks, use cases and practical examples," in Proc. IEEE IoT-SoS, San Francisco, CA, USA, 2012, pp. 1-7. 